\title{
Editorial
}

\section{Polidimensionalidad de los determinantes de la salud en tiempos de COVID-19}

\section{Polidimensionality of the determinants of health in times of COVID-19}

\author{
$\underline{\text { https://doi.org/10.52808/bmsa.7e5.61e2.000 }}$
}

La conceptualización de la salud, a lo largo de la historia ha evolucionado amplia desde el paradigma médicobiológico hasta el socio-ecológico, que engloba al anterior y lo supera; asi se reemplaza la doctrina determinista de la causalidad simple del binomio salud-enfermedad por el marco de proceso multicausal, de acuerdo con el pensamiento científico actual. De allí que la OMS, (2000) define la salud como "el estado completo de bienestar físico, mental y social", concepto que viene acuñándose desde 1948. Desde la perspectiva Colom Masfret, (2014) en el Modelo Biopsicosocial salud y enfermedad son cualitativamente similares y son vistos como un continium, en este caso las personas son vistas como sistemas complejos y la enfermedad sería causada por múltiples factores y no por un único factor causal, podrían ser factores biológicos (virus y bacterias) psicológicos (pensamientos, conductas, emociones) y sociales (economía, familia, comunidad, etc.), el individuo es visto como un ser activo, siendo responsables de su salud.

Otro paradigma "socio-ecológico", plantea un escenario para entender las condiciones y las causas de la salud y la enfermedad e incorpora las actividades relacionadas con la salud como parte de las políticas sociales. Obviamente este paradigma debe integrar las perspectivas biomédicas y psicosociales y ecológicas. Por otra parte, Marc Lalonde, ministro de sanidad Canadiense, en el documento Nuevas Perspectivas de la Salud de los canadienses (1974), enuncio un modelo que ha tenido gran influencia en los últimos años y que establece que la salud de una comunidad esta condicionada por la interacción de cuatro grupos de factores: 1) Estilos de vida y conductas de salud (drogas, sedentarismo, alimentación, estrés, conducción peligrosa, mala utilización de los servicios sanitarios); 2) Biología humana (constitución, carga genética, desarrollo y envejecimiento); 3) Medio ambiente (contaminación física, química, biológica, psicosocial y sociocultural); y 4) Sistema de asistencia sanitaria (mala utilización de recursos, sucesos adversos producidos por la asistencia sanitaria, listas de espera excesivas, burocratización de la asistencia).

Ahora bien, ante el advenimiento de la COVID-19, que ha generado una crisis sanitaria, económica y social de semejante envergadura, es imprescindible integrar la salud en las políticas públicas y diseñar políticas de salud que incorporen la perspectiva de los determinantes polidimemnsionales, donde se consideren la totalidad de los factores de Marc Lalonde, pero con una mirada especial a la emergente información temprana sobre el virus, aunado a un manejo confuso de la emergencia y casuística por las fuentes oficiales, que conmociona a la población. En términos generales, el miedo, especulación y rumores, amplificada y transmitida rápidamente por las modernas tecnologías de la información que afecta negativamente a la sociedad, más el aislamiento y distanciamiento como un factor clave para la protección de la salud, aunado a la necesidad de la obligatoriedad de buscar sustento para sus hogares. De particular importancia, las dimensiones humanas en la educación y la psicología, ya que permiten comprender de manera holística al ser humano, o sea, en su totalidad, pudiendo jerarquizar sus diferentes aspectos fundamentales y comprender mejor cómo se organizan, cómo operan o cuáles reciben prioridad en determinadas circunstancias.

José Antonio Romero Palmera Editor BMSA

https://orcid.org/0000-0002-0675-5565

Referencias

Colom Masfret, D. (2014). Modelos de Trabajo Social Sanitario. La gestión y la clínica. En: Allué Martínez X., Colom Masfret D. y Villalobos Hidalgo J. Contexto histórico en el Trabajo Social Sanitario. Barcelona: FUOC. Disponible en: http://openaccess.uoc.edu/webapps/o2/bitstream/10609/76845/9/Contexto\%20hist\%C3\%B3rico\%20en\%20el\%20TSS M\%C3\%B3dulo\%204_Modelos\%20de\%20trabajo\%20social\%20sanitario.\%20La\%20gesti\%C3\%B3n\%20y\%201a\%20

c1\%C3\%ADnica.pdf (Acceso junio 2021)

Organización Mundial de la Salud (OMS). (2020). Definición de Salud. Disponible en: https://www.who.int/es/about/ who-we-are/ frequently-asked-questions (Acceso junio 2021)

Lalonde, M. (1974). A New Perspective on the Health of Canadians. Ottawa, Ontario, Canada: Information Canada. 